Mechanism of the Conformational Transitions in 6-Hydroxymethyl-7,8-dihydropterin Pyrophosphokinase as Revealed by NMR Spectroscopy ${ }^{\dagger}$

Guangyu $\mathrm{Li}^{1}$, Kristof Felczak ${ }^{2}$, Genbin $\mathrm{Shi}^{3}$, and Honggao Yan ${ }^{*}$

Department of Biochemistry and Molecular Biology, Michigan State University, East Lansing, MI 48824, USA

\title{
Scheme 1
}

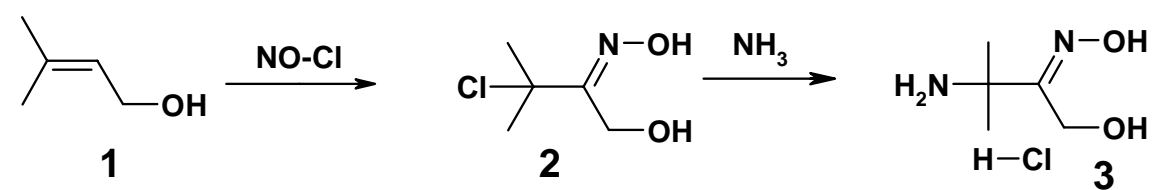<smiles>Nc1nc(Cl)cc(=O)[nH]1</smiles>

4<smiles>CC1(C)Nc2nc(N)[nH]c(=O)c2N=C1CO</smiles>

8<smiles>Nc1nc(Cl)c([N+](=O)[O-])c(=O)[nH]1</smiles><smiles>CC(C)C</smiles>

$$
\mathrm{H}_{2} \mathrm{~N}
$$<smiles>CC(C)(Nc1nc(N)[nH]c(=O)c1[N+](=O)[O-])C(CO)=NO</smiles>

$\mathrm{H}_{2}$<smiles>CC(C)(Nc1nc(N)[nH]c(=O)c1N)/C(CO)=N/O</smiles>

7 


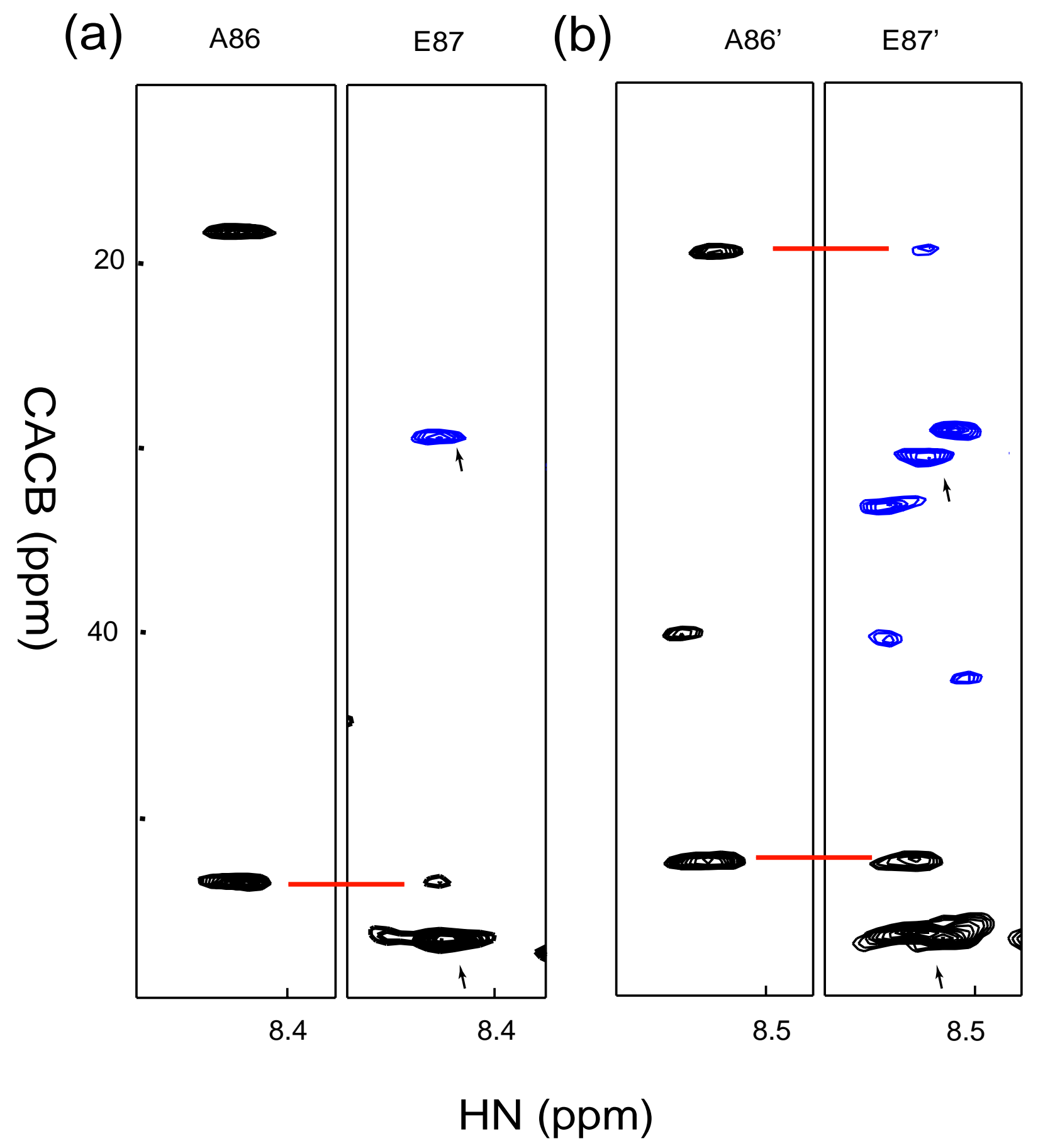

Figure S1. Strip plots of the 3D HNCACB and CBCA(CO)NH spectra of the binary complex

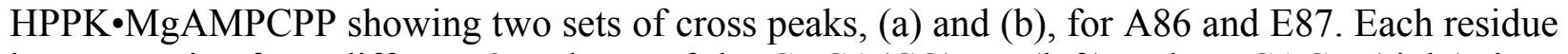
has two strips from different 2D planes of the CBCA(CO)NH (left) and HNCACB (right) data. Horizontal bars across the strips indicate the $C^{\alpha}$ and $C^{\beta}$ connectivities between the residues. The arrows indicate the starting or ending residues of the connected fragments. 


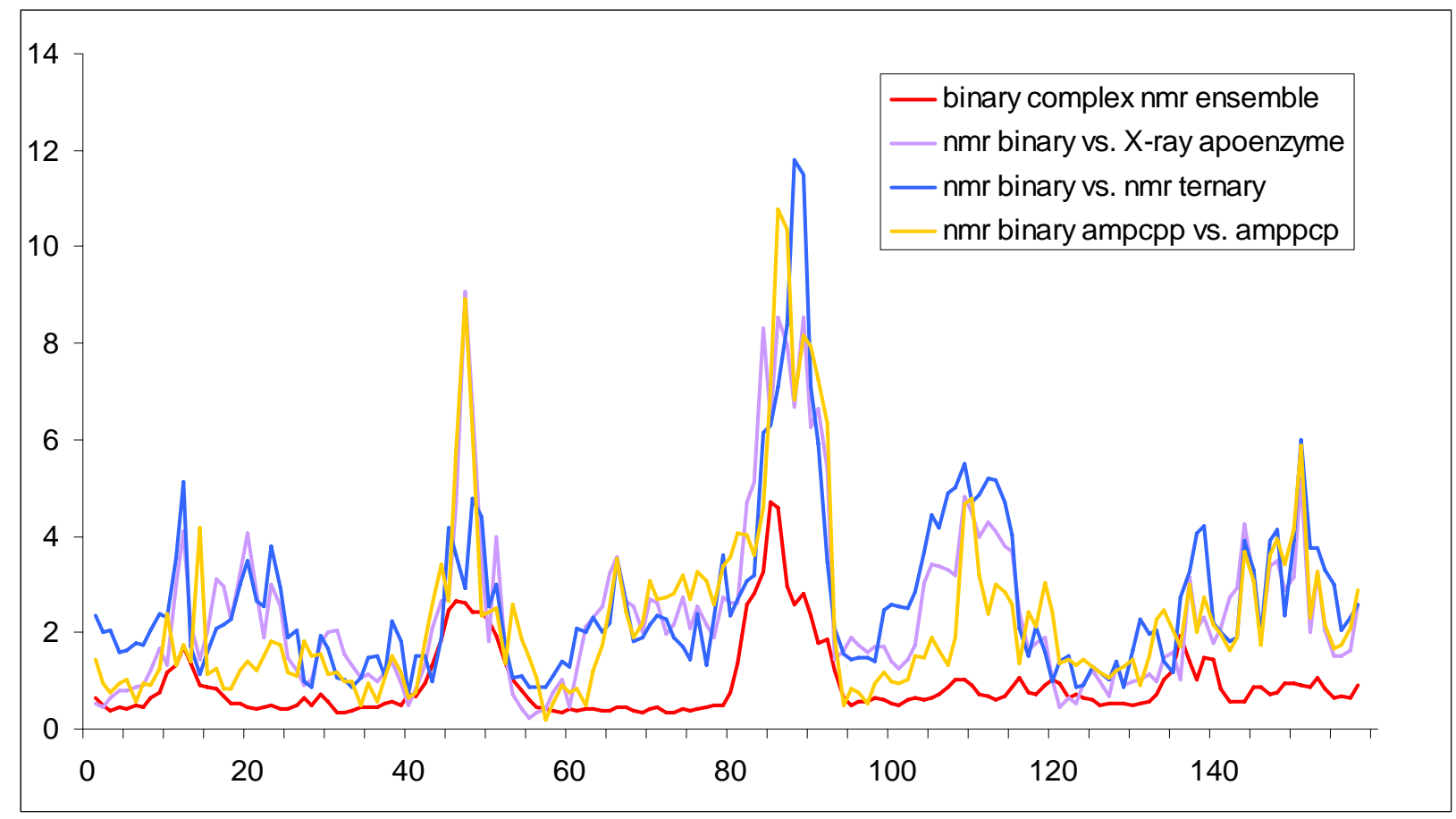

Figure S2. RMSDs of the NMR ensembles of conformers of the binary complex $\mathrm{HPPK} \cdot \mathrm{MgAMPCPP}$ from its mean conformer (red line), the NMR ensembles of conformers of the binary complex HPPK $\cdot \mathrm{MgAMPCPP}$ and the crystal structure of the apo enzyme (pink line), the NMR ensembles of conformers of the binary complex HPPK $\cdot M g A M P C P P$ and the ternary

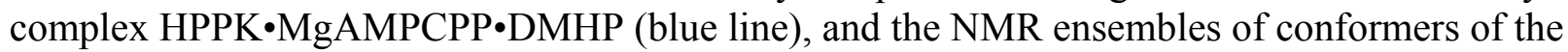
binary complexes HPPK $\bullet \mathrm{MgAMPCPP}$ and HPPK•MgAMPPCP (yellow lines). 


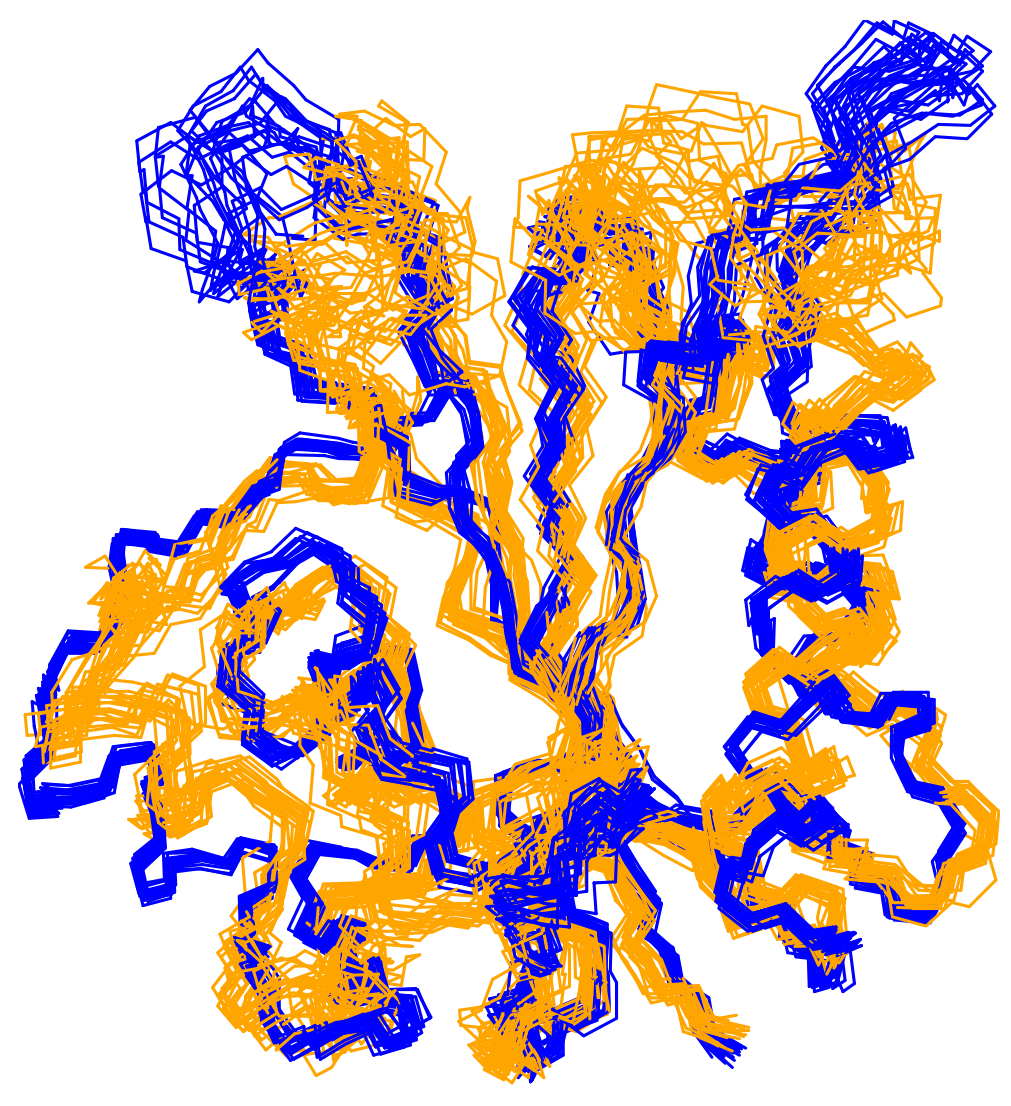

Figure S3. Superposition of the NMR ensembles of conformers of the binary complexes $\mathrm{HPPK} \cdot \mathrm{MgAMPCPP}$ (orange) and HPPK $\bullet \mathrm{MgAMPPCP}$ (blue). 
